\title{
The impact of romance novels on women's sexual and reproductive health
}

\author{
Kundan Iqbal
}

Medical Student, Newcastle University, Newcastle upon Tyne, UK

\section{Correspondence to Ms Kundan lqbal, Newcastle University Medical School, Framlington Place, Newcastle upon Tyne, NE2 4HH, UK; kundan.iqbal@newcastle.ac.uk}

Received 9 June 2014 Accepted 19 June 2014 Published Online First 17 July 2014

\section{INTRODUCTION}

Romance novels are defined broadly as fiction focused on a central love story, which is concluded in an emotionally satisfying and optimistic manner. Romance is one of the most popular genres, accounting for the largest market share in fiction. ${ }^{1}$ In 2009, romantic fiction generated approximately $\$ 1.4$ billion in the USA alone. ${ }^{1}$ The popularity of the romantic genre shows no sign of abating; indeed, the number of Americans who read at least one romance novel that year increased from 64.6 million in 2007 to 74.8 million in $2008 .^{1}$ Almost one in four Americans read a romance novel in $2008 .^{1}$

It has been well established that the attitudes and behaviours of consumers are affected by exposure to portrayals of sex and sexuality in the media. ${ }^{1-3}$ Much research has been conducted on visual media (i.e. television, film, music videos and magazines). ${ }^{1-3}$ However, despite their widespread readership, very little research has been done on depictions of sexual behaviours in romance novels. Seemingly innocuous and entertaining escapism, can romance novels potentially influence readers' attitudes, beliefs and sexual health behaviour?

\section{NEGATIVE IMPACT OF ROMANTIC FICTION}

Romantic literature can account for a large part of women's exposure to sexuality and relationships. Some avid fans can spend as much as a day a week reading it. ${ }^{4}$ It has been pointed out that, in contrast, women's exposure to formal sex and relationships education may be as little as a few hours in a lifetime. ${ }^{4}$

Contemporary romances have generally moved away from dated stereotypes to more realistic and modern relationships, which can feature challenges such as addiction, single parenting or domestic violence. ${ }^{4}$ However, romantic novels still typically end with the male and female protagonist in a joyful, effortless and deeply fulfilled relationship. Some argue in favour of this enjoyable fantasy, such as the popular writer Meg Cabot who states: "Life isn't a romance novel ... the reason romance novels sell so well - the reason why everyone loves them - is because no one's life is actually like that. Everyone wants their life to be like that". ${ }^{5}$

In contrast, others suggest the very escapism of romantic fiction promotes psychosexual problems. Romantic fiction has been criticised for purveying an idealised depiction of love and sex that often leaves out the "unromantic, awkward, unseemly, and messy bits". ${ }^{4}$ Writer Suzette Henke asks: "What works of modern literature portray a woman inserting a diaphragm? Vertiginous from morning sickness? ... All these physiological events are, perhaps, too messy, violent, or indelicate to be part of women's literary consciousness". ${ }^{2}$ Consumer Correspondent for the Journal of Family Planning and Reproductive Health Care, Susan Quilliam, argues that sex and relationships are never perfect and that idealising them is misleading and undesirable. ${ }^{4}$ Whilst supporting the widespread popularity of the genre and fully acknowledging its usefulness when combined with robust sexual health education, Quilliam criticises romantic novels for propagating unhelpful messages such as the notion that a woman's first time is invariably joyful and that frequent pregnancy is proof of a relationship's strength. ${ }^{4}$ An analysis of romantic content in bestselling fiction novels found that romantic partners are depicted as constantly available for and desiring sex. ${ }^{6}$ In addition, romance novels commonly depict easily achievable and remarkable orgasms for both sexes, with females often experiencing multiple orgasms. ${ }^{6}$ A study analysing 
91 depictions of orgasm across 16 award-winning romance books found almost half depicted simultaneous orgasm; and in popular culture, depictions of perfect simultaneous orgasms are used as 'evidence' of true love. ${ }^{6}$ These experiences are not reflected in real-life scenarios and may lead to unrealistic expectations, disappointment and frustration. ${ }^{4} 6$ Whilst "readers are likely to be impacted differently ... it is possible that a portion of readers may derive unrealistic expectations or beliefs about their own sexual experiences from these novels". ${ }^{6}$ Conversely, author Jude Deveraux rubbishes this concern, stating: "[Supposedly] women who read [romantic novels] are so stupid that they can't tell a story from reality. Is anyone worried that the men who read spy thrillers are going to go after their neighbours with an automatic weapon?" 7

Romance novels have also been criticised for perpetuating gender roles. A study examining sexual behaviours depicted in contemporary romance novels found that they confirmed the gender role sexual stereotypes seen in other forms of media and in the minds of the general population. ${ }^{1}$ Men are often depicted as perpetually aroused and more likely to initiate sexual contact, reinforcing the notion that women should be sexually passive. ${ }^{18}$ However, more recent novels have shown an increasing incidence of positive female initiation of sexual encounters; nevertheless, there is a relatively greater increase in scenarios where both partners initiate. " "This finding might indicate that while it is acceptable for women to initiate sex, it is still not preferable that women make the first move on their own". ${ }^{1}$

A major concern is the still largely absent depiction of contraception in fictional romantic plots. In a 2000 study analysing 78 novels, only 1 in 10 mentioned the possibility of condom use; and birth control or sexually transmitted infection prevention were only rarely discussed. ${ }^{8}$ A study carried out in 2011 found a significant difference in attitudes towards contraception between earlier (1989-1999) and more contemporary (20002009) novels, with contraception (usually male condoms) used in $18.5 \%$ compared to $57.9 \%$ of scenes, respectively. ${ }^{1}$ In spite of this, contraception usage rates remain relatively low even in recently published books, and in many books there are no references whatsoever to its use. ${ }^{1}$ Contraception is rarely discussed even when it is used (i.e. deliberation over its use, reasons for using it) and it is always initiated by the male protagonist, perpetuating the passive role of women in the romantic script. ${ }^{18}$ In the rare discussions that did occur surrounding contraceptives, "the heroine typically rejected the idea because she wanted 'no barrier' between her and the hero". ${ }^{4}$ On occasion the appearance of birth control is the vehicle of comedy or disaster. ${ }^{2}$ Rarely is contraception portrayed as an important and empowering means of sexual health.

The role of sexual responsibility has also been explored in young adult literature, which caters to a younger and arguably more impressionable audience. ${ }^{3}$ It is claimed that leisure reading constitutes an important influence on adolescent sexual understanding. ${ }^{9}$ Twenty-five works of young adult fiction that depicted sexual themes involving contraception were analysed in a recent study. ${ }^{9}$ Results showed that of the 36 heterosexual relationships portrayed, contraception was used at least once in $74 \%$ of those relationships. ${ }^{9}$ However, only one-third of the books provided enough details about contraception to make them helpful, informative sources for readers and only one-quarter portrayed contraceptive experiences as positive. ${ }^{9}$ Similar results were found in an analysis of the top 40 best-selling adolescent books, which discovered an abundance of sexual material, especially in female-orientated novels. ${ }^{3}$ However, the novels rarely if ever dealt with issues of abstinence, safe sex practices and the risks and consequences associated with sex. ${ }^{3}$ The rare instances where consequences were mentioned were emotional in nature; unwanted pregnancy, abortion and disease were never alluded to. ${ }^{3}$ The authors commented that "this lack of consequence and discussion of potential risks ... may remove perceived barriers or concerns among adolescents that would otherwise encourage them to think more carefully or cautiously about sexual behaviour". ${ }^{3}$

Equally worryingly, other researchers have called attention to the glamorisation of non-consensual sex, ${ }^{4}$ and physical and emotional intimate abuse patterns in certain hugely popular romantic novels. ${ }^{10}$ Thus, it is argued that there is a conflict between the messages propagated in romantic fiction and the healthy sexual and reproductive behaviours health care professionals wish to encourage in their clients.

\section{POSITIVE IMPACT OF ROMANTIC FICTION}

Conversely, reading romance novels is correlated with certain positive aspects. Romantic novels often openly and sometimes explicitly portray female sexuality, desire and the act of intercourse, usually in a positive and liberating manner. This can allow readers to "contextualise and normalise their own feelings of desire, in turn influencing their acceptance of sexual expression in the broader popular culture". ${ }^{2}$ This "liberation of sexuality" is celebrated by many women. ${ }^{4}$

Romantic literature can lead to improved sexual confidence, greater sexual activity and greater sexual experimentation. ${ }^{4}{ }^{11}$ Surveys have demonstrated that many readers of the genre use romantic literature to foster a healthy monogamous relationship while simultaneously vicariously fulfilling sexual desires. ${ }^{4} 11$ Women who read romance novels also reported that they did not negatively compare their real-life partners with fictional male protagonists or heroes, unless already unhappy in their relationship. ${ }^{11}$

\section{INFLUENCE ON REAL-LIFE BEHAVIOUR}

Does the content of fictional literature impact real-life sexual health choices? A 2009 survey that questioned 
whether sexual themes in young adult literature influenced teens' own sexual experiences showed that fewer than $15 \%$ across all ages said novels often influence them and $32-58 \%$ (depending on age) said literature never influences their choices, with the remainder stating a variable influence. The primary reason adolescents gave for choosing to read fiction with sexually explicit content was entertainment. ${ }^{12}$ In a study of adult participants, study subjects stated that they use romance novels primarily for recreational enjoyment and emphasised their awareness of the fictional nature of romance novels. ${ }^{11}$ Most denied any impact of reading romance novels on their sexual behaviour or knowledge; with regard to safer sex practices, most participants said they discounted the information presented in romance novels as unreliable. ${ }^{11}$ Thus, some argue, romance novels are unlikely to exert undue influence on attitudes and behaviours. ${ }^{4}$

In contrast, Diekman and colleagues disagree, suggesting that "although romance readers may be fully aware that the portrayals of spontaneous, passionate, and risk-free sexual encounters are fictional, they nonetheless are likely to form beliefs and expectations based on such reading". ${ }^{8}$ Indeed, research shows consumption of romance novels may have a significant effect on readers' sexual health attitudes and behaviours. ${ }^{6} 8$ Fictional information is easily incorporated into memory, even if clearly false. ${ }^{8}$ This is compounded by the stimulation and vividness of the narrative medium. ${ }^{8}$ Research demonstrates a clear correlation between the frequency of reading romance and the level of negative attitudes towards condoms and intention to use them in the future, despite the study subjects' awareness of the fictional element. ${ }^{8}$ Including safe sex elements in romantic fiction increased positive attitudes toward condoms and marginally increased future intent to use condoms. ${ }^{8}$ Other research suggests these novels promote specific values and expectations around sexuality and sexual responsibility, for example, expectations about high sexual desire. $^{6} 8$ However, it remains unclear whether romance novels influence readers' attitudes and beliefs or whether they preferentially attract readers with particular attitudes towards sexuality. ${ }^{6}$

\section{CONCLUSIONS}

Romantic literature is an enduringly popular genre, enjoyed by many women. Romance novels can introduce women to potential positive effects in their sex lives. However, whilst ostensibly harmless escapism, romance novels can also perpetuate the myth of effortless and romantic sexual encounters and influence crucial aspects of readers' sexual health attitudes and behaviours. Ideally, romantic fiction can function to both entertain and educate readers, by combining them with clear and comprehensive continuing public sexual education, via the promotion of realistic expectations and depictions of safer sexual practices.

Competing interests None.

Provenance and peer review Not commissioned; externally peer reviewed.

\section{REFERENCES}

1 Dana Ménard A, Cabrera C. Whatever the approach, tab B still fits into slot A: twenty years of sex scripts in romance novels. Sex Cult 2011;15:240-255.

2 Capo BW. Textual Contraception: Birth Control and Modern American Fiction. Columbus, $\mathrm{OH}$ : The Ohio State University Press, 2007.

3 Callister M, Coyne SM, Stern LA, et al. A content analysis of the prevalence and portrayal of sexual activity in adolescent literature. J Sex Res 2011;49:477-486.

4 Quilliam S. "He seized her in his manly arms and bent his lips to hers...". The surprising impact that romantic novels have on our work. J Fam Plann Reprod Health Care 2011;37:179-181.

5 Cabot M. The Princess Diaries: Ten out of Ten. London, UK: Harper Collins, 2009.

6 Cabrera C, Ménard A. "She exploded into a million pieces": a qualitative and quantitative analysis of orgasms in contemporary romance novels. Sex Cult 2013;17:193-212.

7 Deveraux J. Remembrance. New York, NY: Pocket Books, 1997.

8 Diekman AB, Gardner WL, McDonald M. Love means never having to be careful: the relationship between reading romance novels and safe sex behavior. Psychol Women $Q$ 2000;24:179-188.

9 McDermott JT. Getting it on: an examination of how contraceptives are portrayed in young adult literature. Young Adult Lib Ser 2011;9:47-53.

10 Bonomi AE, Altenburger LE, Walton NL. "Double crap!" Abuse and harmed identity in Fifty Shades of Grey. J Womens Health (Larchmt) 2013;22:733-744.

11 Anderton G. Excitement, Adventure, Indifference: Romance Readers' Perceptions of How Romance Reading Impacts Their Sex Lives. Chester, PA: Center for Education, Widener University, 2009.

12 Wood E. Pushing the envelope: exploring sexuality in teen literature. Journal of Research on Libraries and Young Adults, posted in 2010 Symposium Poster Presentations, Volume 1, Number 1, November 2010. 